\title{
Inhibition of in vitro lipid peroxidation by stable steroidic nitroxyl radicals
}

\author{
Giuliana Cighetti ${ }^{\mathrm{a}, *}$, Pietro Allevi ${ }^{\mathrm{a}}$, Sandra Debiasi ${ }^{\mathrm{a}}$, Rita Paroni ${ }^{\mathrm{b}}$ \\ a Department of Medical Chemistry and Biochemistry, Faculty of Medicine, University of Milan, Via Saldini 50, 20133 Milan, Italy \\ b Scientific Institute San Raffaele, Via Olgettina 60, 20132 Milan, Italy
}

Received 28 March 1997; received in revised form 12 June 1997; accepted 3 July 1997

\begin{abstract}
4',4'-dimethylspiro ( $5 \alpha$-cholestane-3,2'-oxazolidin)-3'-yloxy (IK-1) and $7 \alpha, 12 \alpha$-dihydroxy-4', $4^{\prime}$-dimethylspiro $(5 \beta$ cholan-24-oic-3,2'-oxazolidin)-3'-yloxy acid (IK-2), two stable steroidic nitroxyl radicals, were newly synthesized and tested as possible inhibitors of lipid peroxidation, induced by Fenton's reagent in both rat liver microsomes and egg phosphatidylcholine liposomes. The inhibitory activity, evaluated through the formation of thiobarbituric acid reactive substances (TBARS) and the conjugated diene, was compared with that of $\alpha$-tocopherol and 2,2,6,6-tetramethylpiperidine-1-yloxy (TEMPO). In each model system IK-1 and IK-2 exhibited an $\mathrm{IC}_{50}$ of $8 \mu \mathrm{M}$ and reduced the formation of TBARS and conjugated diene, showing IK-1 a potency comparable to $\alpha$-tocopherol and higher than TEMPO. Moreover IK-1 and, to a lesser extent IK-2, reduced the lipid peroxidation induced in the microsomes by the water-soluble azo-initiator 2,2'-Azobis (2-methylpropionamidine) dihydrochloride (AMPH), indicating the IK-1 and IK-2 ability as chain-breaking antioxidants. The hydroxylamine $4^{\prime}, 4^{\prime}$-dimethylspiro ( $5 \alpha$-cholestane-3, $2^{\prime}$-oxazolidin)-3'-hydroxide (IK-3), obtained by chemical reduction of IK-1, was completely inactive as an inhibitor of lipid peroxidation in heat pre-treated microsomes and in liposomes. However in microsomes it was active since it was oxidized to the corresponding nitroxyl radical IK-1. (c) 1997 Elsevier Science Ireland Ltd.
\end{abstract}

Keywords: Lipid peroxidation; Free radicals; Nitroxyl radicals

\footnotetext{
Abbreviations: AMPH, 2,2'-Azobis (2-methylpropionamidine) dihydrochloride; BHT, butylated hydroxytoluene; HPLC, high-performance liquid chromatography; IK-1, 4',4'-dimethylspiro ( $5 \alpha$-cholestane-3,2'-oxazolidin)-3'-yloxy; IK-2, $7 \alpha, 12 \alpha$-dihydroxy-4', $4^{\prime}$ dimethylspiro (5 $\beta$-cholan-24-oic-3,2'-oxazolidin)-3'-yloxy acid; IK-3, 4',4'-dimethylspiro (5 $\alpha$-cholestane-3,2'-oxazolidin)-3'hydroxide; NMR, nuclear magnetic resonance; TBA, thiobarbituric acid; TBARS, thiobarbituric reactive substances; TCA, trichloroacetic acid; TEMPO, 2,2,6,6-tetramethylpiperidine-1-yloxy; TLC, thin-layer chromatography; Xan, xanthine; XO, xanthine oxidase.

* Corresponding author. Tel.: + 392 70645225; fax: + 392 2361407; e-mail: skinski@imiucca.csi.unimi.it
} 


\section{Introduction}

Oxygen free-radicals and metabolites that derive from lipid peroxidation are implicated in various cell injuries and in many pathological situations (Halliwell et al., 1992; Esterbauer et al., 1993). Thus many studies have been focused on selecting antioxidants able to prevent free-radical damage. Some of these have shown that simple nitroxyl radicals, previously used as spin labels for electron spin resonance spectroscopy, are able to inhibit lipid peroxidation in various ways. In fact these nitroxyl radicals react with, and dismutate, superoxide radical anions $\left(\mathrm{O}_{2}^{-}\right)$in a catalytic fashion that mimics that of superoxide dismutase (Mitchell et al., 1990; Samuni et al., 1991), competing with $\mathrm{H}_{2} \mathrm{O}_{2}$ in the oxidation of $\mathrm{Fe}^{2+}$ ions (Voest et al., $1994)$ and preventing hydroxyl radical $\left(\mathrm{OH}^{*}\right)$ formation (Gelvan et al., 1991). However some of these simple nitroxyl radicals show, together with these favourable effects, undesirable properties like negative chronotropy and anaesthetic effects that prevent their use in pharmacology (Gelvan et al., 1991). Thus, some authors have devoted their efforts to finding new radical scavengers and, considering that membrane compartments are the principal peroxidation site, have searched for new lipophilic nitroxyls which, on interacting with biomembranes, could accumulate in this specific site. As a result of this research, some non cytotoxic stearic acid derivates binding a nitroxyl radical (doxyl stearates) have been found capable of reducing lipid peroxidation, acting as chain-breaking antioxidants in microsomes (Ankel et al., 1987; Nilsson et al., 1989; Miura et al., 1993).

As part of a wider program devoted to studying various aspects of lipid peroxidation (Allevi et al., $1995 \mathrm{a}, \mathrm{b})$ now we report that $4^{\prime}, 4^{\prime}$-dimethylspiro ( $5 \alpha$-cholestane-3,2'-oxazolidin)-3'-yloxy (IK-1) and $7 \alpha, 12 \alpha$-dihydroxy-4', $4^{\prime}$-dimethylspiro $(5 \beta-$ cholan-24-oic-3,2'-oxazolidin)-3'-yloxy acid (IK2), two newly synthesized stable and lipophilic steroidic nitroxyl radicals derived from cholestane and cholic acid respectively, decrease lipid peroxidation in microsomes and liposomes subjected to artificial peroxidation. In the presence of a microsomal enzymatic system the hydroxylamine $4^{\prime}, 4^{\prime}$ dimethylspiro (5 $\alpha$-cholestane-3,2'-oxazolidin)-3'- hydroxide (IK-3) derived from IK-1, is transformed into the parent nitroxyl compound and thus affords protection against radicals.

\section{Experimental procedures}

\subsection{Laboratory materials}

2,2,6,6-Tetramethylpiperidine-1-yloxy

(TEMPO), butylated hydroxytoluene (BHT), 2,2'Azobis (2-methylpropionamidine) dihydrochloride (AMPH), $5 \alpha$-cholestan-3-one and $\alpha$-tocopherol were obtained from Aldrich (Milwaukee, WI). Trichloroacetic acid (TCA), thiobarbituric acid (TBA) and all reagents were purchased from Sigma (St. Louis, Mo). Xanthine (Xan), butter milk Xanthine Oxidase (XO) $(0.4 \mathrm{U} / \mathrm{mg}$ protein) and phosphatidylcholine from dried egg yolk were from Fluka Chemika (Buchs, Switzerland).

Melting points $(\mathrm{mp})$ were determined on a Büchi 510 capillary melting point apparatus and are uncorrected. ${ }^{1} \mathrm{H}$ NMR spectra were obtained on a Bruker AM-500 instrument for solutions in $\mathrm{CDCl}_{3}$ at $303 \mathrm{~K}$ and are reported in $\delta$ units relative to $\mathrm{CDCl}_{3}$ fixed at $7.24 \mathrm{ppm}$. Thin-layer chromatographic analysis (TLC) was carried out on silica gel HF 254 microplates to monitor reaction progress. Spots were visualized by spraying the developed plates with $70 \%$ sulfuric acid solution followed by heating for $5-10 \mathrm{~min}$ at $110^{\circ} \mathrm{C}$. High-performance liquid chromatography (HPLC) analysis was performed on a Jasco twinkle pump system, a VL 614 variable-loop injector with a $20 \mu 1$ sample loop and on a Uvidec 100 II. The recorder was a Shimadzu C-R 3A Chromatopac. The HPLC analysis for IK-1 detection was carried out on an Apex Octadecyl 5U column (15 $\mathrm{cm}, 3 \mu \mathrm{m}, 0.46 \mathrm{~cm}$ i.d.) (Jones Chromatography, UK) using methanol as the mobile phase; the flow rate was $1 \mathrm{ml} / \mathrm{min}$ and detection was performed at $250 \mathrm{~nm}$ instead of $232 \mathrm{~nm}$ (maximum absorbance of IK-1) to reduce phospholipid interference. The UV assay was carried out with a Perkin Elmer Lamda11 recording spectrophotometer (PerkinElmer GmbH, Germany). 

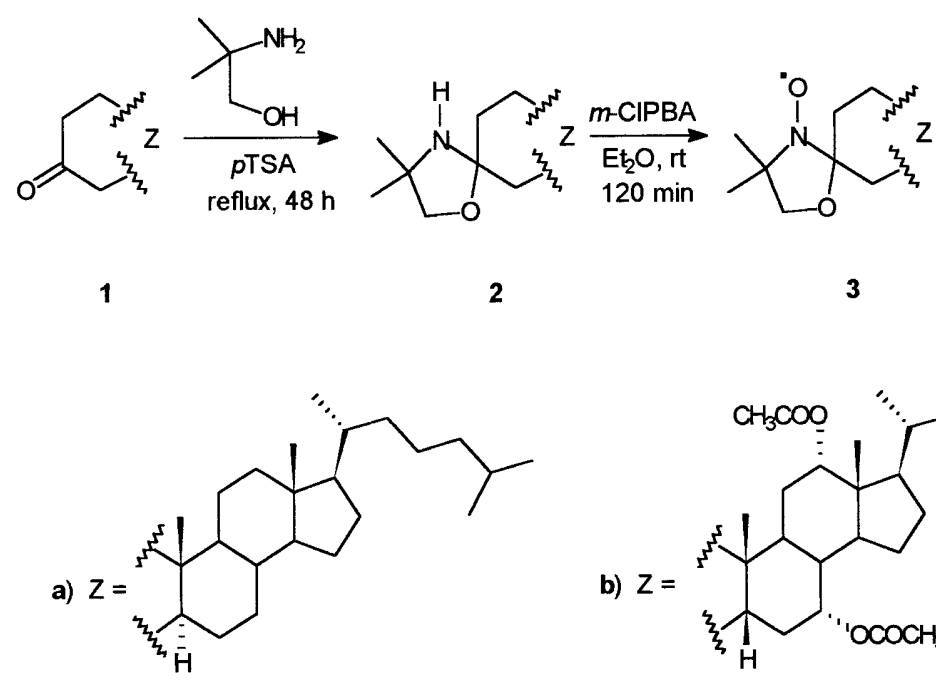

b) $Z=$

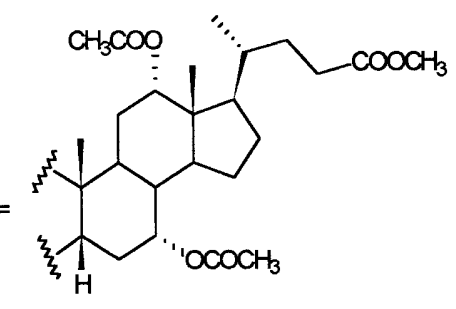

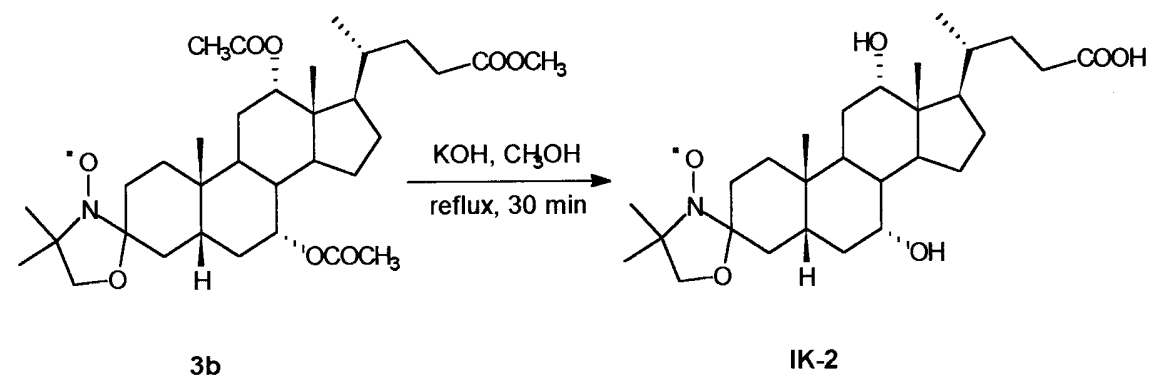

Fig. 1. Synthesis of $4^{\prime}, 4^{\prime}$-dimethylspiro ( $5 \alpha$-cholestane-3,2'-oxazolidin)-3'-yloxy (3a: IK-1) and $7 \alpha, 12 \alpha$-dihydroxy-4', $4^{\prime}$-dimethylspiro (5 $\beta$-cholan-24-oic-3, $2^{\prime}$-oxazolidin)-3'-yloxy acid (IK-2).

\subsection{Synthesis of 4',4'-dimethylspiro}

(5 $\alpha$-cholestane-3,2'-oxazolidin)-3'-yloxy (3a:

$I K-1)$ and $7 \alpha, 12 \alpha$-dihydroxy-4',4'-dimethylspiro

(5 $\beta$-cholan-24-oic-3,2'-oxazolidin)-3'-yloxy acid $(I K-2)$

The introduction of the doxyl moiety into the steroidic nucleus of cholestane or cholic acid was done by the following two-step general procedure (Fig. 1). A solution containing the steroidic ketone $\mathbf{1 a}$ or $\mathbf{1 b}(7.8 \mathrm{mmol})$, 2-amino-2-methylpropan-1-ol $(2 \mathrm{ml} ; 21 \mathrm{mmol})$ and $p$-toluensulfonic acid $(20 \mathrm{mg})$ in toluene $(150 \mathrm{ml})$ was refluxed for $48 \mathrm{~h}$ with continuous water removal by means of a Dean-Stark trap. The solution was then cooled, washed with saturated aqueous $\mathrm{NaHCO}_{3}$ solution and dried over $\mathrm{MgSO}_{4}$. The solvent was eliminated under reduced pressure to afford a crude residue, an inseparable mixture of epimers that showed the appropriate physico-chemical properties and that was used in the successive reaction without purification. Starting from $5 \alpha$-cholestan3-one 1a, we obtained $2 \mathrm{a}$ (3.28 g, 92\% yield): $\mathrm{mp}$ $123-125^{\circ} \mathrm{C}$ (from methanol), (Lit.: $124-125^{\circ} \mathrm{C}$ ) (Keana et al., 1967); ${ }^{1} \mathrm{H}$ NMR: $\delta 3.55$ (2H, AB system, $5^{\prime}-\mathrm{H}$ and $\left.5^{\prime}-\mathrm{H}\right), 1.21\left(6 \mathrm{H}, \mathrm{s}, 4^{\prime}-\mathrm{CH}_{3}\right.$ and $\left.4^{\prime}-\mathrm{CH}_{3}\right), 0.87\left(3 \mathrm{H}, \mathrm{d}, J 6.5 \mathrm{~Hz}, 21-\mathrm{CH}_{3}\right), 0.84(3 \mathrm{H}$, d, $J 7.0 \mathrm{~Hz}, 26$-or $\left.27-\mathrm{CH}_{3}\right), 0.83(3 \mathrm{H}, \mathrm{d}, J 7.0 \mathrm{~Hz}$, 27-or 26- $\left.\mathrm{CH}_{3}\right), 0.75\left(3 \mathrm{H}, \mathrm{s}, 19-\mathrm{CH}_{3}\right), 0.62(3 \mathrm{H}, \mathrm{s}$, 18- $\mathrm{CH}_{3}$ ). Analysis calculated for $\mathrm{C}_{31} \mathrm{H}_{55} \mathrm{NO}$ : C, 81.34, H, 12.11, N, 3.06; found: C, 81.20, H, $11.95, \mathrm{~N}, 3.15$. Starting from methyl $7 \alpha, 12 \alpha$-diace- 


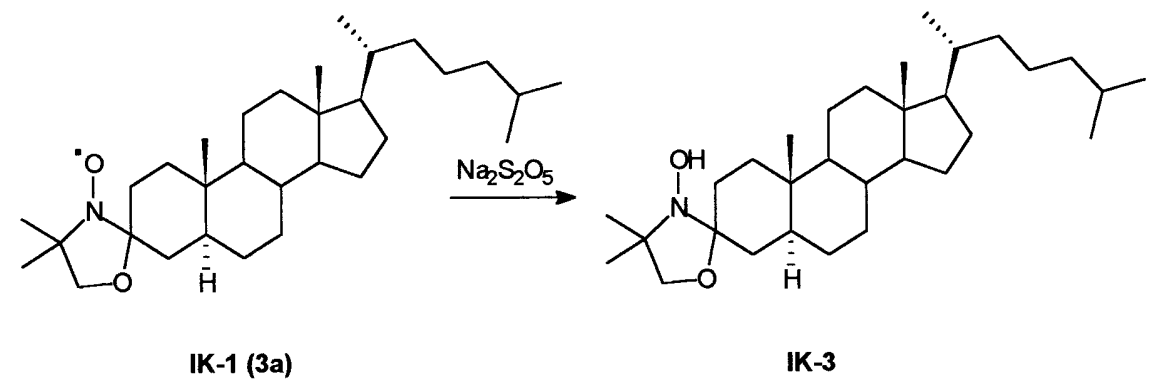

Fig. 2. Synthesis of 4',4'-dimethylspiro ( $5 \alpha$-cholestane-3,2'-oxazolidin)-3'-hydroxide (IK-3).

toxy-3-oxo-5 $\beta$-cholan-24-oate $\mathbf{1 b}$, prepared as described (von Grand and Reichstein, 1945), we obtained $\mathbf{2 b}$ as a resinous material, $(4.08 \mathrm{~g}, 91 \%$ yield); ${ }^{1} \mathrm{H}$ NMR (major epimer): $\delta 5.02(1 \mathrm{H}, \mathrm{dd}, J$ 2.8 and $J 2.8 \mathrm{~Hz}, 12 \beta-\mathrm{H}), 4.85(1 \mathrm{H}$, ddd, $J 6.3, J$ 3.5 and $J 3.5 \mathrm{~Hz}, 7 \beta-\mathrm{H}), 3.50(2 \mathrm{H}, \mathrm{AB}$ system, $5^{\prime}-\mathrm{H}$ and $\left.5^{\prime}-\mathrm{H}\right), 1.20\left(6 \mathrm{H}, \mathrm{s}, 4^{\prime}-\mathrm{CH}_{3}\right.$ and $\left.4^{\prime}-\mathrm{CH}_{3}\right)$, $0.89\left(3 \mathrm{H}, \mathrm{s}, 19-\mathrm{CH}_{3}\right), 0.76(3 \mathrm{H}, \mathrm{d}, J 6.2 \mathrm{~Hz}$, $\left.21-\mathrm{CH}_{3}\right), 0.67\left(3 \mathrm{H}, \mathrm{s}, 18-\mathrm{CH}_{3}\right)$. Analysis calculated for $\mathrm{C}_{33} \mathrm{H}_{53} \mathrm{NO}_{7}$ : C, 68.84, $\mathrm{H}, 9.28, \mathrm{~N}, 2.43$; found: C, 68.97, H, 9.35, N, 2.49 .

To a solution of the appropriate oxazolidine $(2 \mathbf{a}$ or $\mathbf{2 b} ; 6.13 \mathrm{mmol})$ in diethyl ether $(100 \mathrm{ml})$, $m$-chloroperbenzoic acid $(1.27 \mathrm{~g} ; 7.36 \mathrm{mmol})$ dissolved in diethyl ether $(50 \mathrm{ml})$ was added dropwise at $0^{\circ} \mathrm{C}$. The resulting solution was stirred at room temperature for $120 \mathrm{~min}$. Then the organic layer was washed with saturated aqueous $\mathrm{NaHCO}_{3}$ solution and dried over $\mathrm{Na}_{2} \mathrm{SO}_{4}$. The removal of the solvent under reduced pressure afforded the crude nitroxyl derivative which was purified by rapid chromatography (Still et al., 1978). The title compound 3a (IK-1) was obtained in 68\% yield (hexane/ethyl acetate, 100:10 v/v): $\mathrm{mp} 174-176^{\circ} \mathrm{C}$ (from methanol) (Lit.: 175$176^{\circ} \mathrm{C}$ ) (Keana et al., 1967). The ${ }^{1} \mathrm{H}$ NMR spectrum of this compound showed, however, considerable line broadening, as expected for the paramagnetic nitroxyl moiety present. A well resolved, informative ${ }^{1} \mathrm{H}$ NMR spectrum was obtained by reducing, in situ, the $\mathrm{CDCl}_{3}$ solution of 3a with 1.5 equivalents of phenylhydrazine (Lee and Keana, 1975). ${ }^{1} \mathrm{H}$ NMR: $\delta 3.60(2 \mathrm{H}, \mathrm{AB}$ system, $5^{\prime}-\mathrm{H}$ and $\left.5^{\prime}-\mathrm{H}\right), 1.22$ and $1.23(6 \mathrm{H}, 2 \times \mathrm{s}$, $4^{\prime}-\mathrm{CH}_{3}$ and $\left.4^{\prime}-\mathrm{CH}_{3}\right), 0.89(3 \mathrm{H}, \mathrm{d}, J 6.5 \mathrm{~Hz}, 21-$ $\left.\mathrm{CH}_{3}\right), 0.86\left(3 \mathrm{H}, \mathrm{d}, J 6.8 \mathrm{~Hz}, 26\right.$-or $\left.27-\mathrm{CH}_{3}\right), 0.85$ $\left(3 \mathrm{H}, \mathrm{d}, J 6.8 \mathrm{~Hz}, 26-\right.$ or $\left.27-\mathrm{CH}_{3}\right), 0.80(3 \mathrm{H}, \mathrm{s}$, $\left.19-\mathrm{CH}_{3}\right), 0.64\left(3 \mathrm{H}, \mathrm{s}, 18-\mathrm{CH}_{3}\right)$. Analysis calculated for $\mathrm{C}_{31} \mathrm{H}_{54} \mathrm{NO}_{2}$ : C, 78.76, $\mathrm{H}, 11.51, \mathrm{~N}, 2.96$; found: C, 78.72, H, 11.65, N, 2.90 .

The protected compound $\mathbf{3 b}$ was obtained in $70 \%$ yield (hexane/ethyl acetate, 60:40 v/v). To obtain IK-2, the protected compound $\mathbf{3 b}(342 \mathrm{mg}$, $0.58 \mathrm{mmol})$ was dissolved in methanol $(30 \mathrm{ml})$ and treated with a $\mathrm{KOH}$ methanolic solution $(5 \mathrm{M}, 9$ $\mathrm{ml}$ ) at reflux for $30 \mathrm{~min}$. The solution was cooled at room temperature and concentrated (up to 5 $\mathrm{ml})$ under reduced pressure. After addition of cold water $(10 \mathrm{ml})$, the mixture was acidified with $5 \mathrm{~N}$ $\mathrm{HCl}$ and extracted with trichloromethane $(2 \times 10$ $\mathrm{ml})$. The organic layer was washed with water and dried over $\mathrm{Na}_{2} \mathrm{SO}_{4}$. The evaporation of the solvent under reduced pressure afforded the title compound IK-2 (254 mg, 89\% yield). ${ }^{1} \mathrm{H}$ NMR was recorded after reduction, in situ, by addition of 1.5 equivalents phenylhydrazine. ${ }^{1} \mathrm{H}$ NMR: $\delta$ $3.77\left(1 \mathrm{H}, \mathrm{d}, \mathrm{A}\right.$ part of AB system, $\left.J 9.0 \mathrm{~Hz}, 5^{\prime}-\mathrm{H}\right)$, $3.70\left(1 \mathrm{H}, \mathrm{d}, \mathrm{B}\right.$ part of AB system, $\left.J 9.0 \mathrm{~Hz}, 5^{\prime}-\mathrm{H}\right)$, $1.32\left(3 \mathrm{H}, \mathrm{s}, 4^{\prime}-\mathrm{CH}_{3}\right), 1.31\left(3 \mathrm{H}, \mathrm{s}, 4^{\prime}-\mathrm{CH}_{3}\right), 0.92$ $\left(3 \mathrm{H}, \mathrm{d}, J 6.5 \mathrm{~Hz}, 21-\mathrm{CH}_{3}\right), 0.89\left(3 \mathrm{H}, \mathrm{s}, 19-\mathrm{CH}_{3}\right)$, $0.65\left(3 \mathrm{H}, \mathrm{s}, 18-\mathrm{CH}_{3}\right)$. Analysis calculated for $\mathrm{C}_{28} \mathrm{H}_{46} \mathrm{NO}_{6}$. C, 68.26, H, 9.41, N, 2.84; found: C, 68.18, H, 9.47; N, 2.78.

\subsection{Preparation of 4',4'-dimethylspiro (5 $\alpha$-cholestane-3,2'-oxazolidin)-3'-hydroxide $(I K-3)$}

The compound 3a (IK-1) $(47 \mathrm{mg} ; 0.1 \mathrm{mmol})$ in ethyl acetate $(30 \mathrm{ml})$ was shaken with a saturated aqueous solution of $\mathrm{Na}_{2} \mathrm{~S}_{2} \mathrm{O}_{5}(50 \mathrm{ml})$ until the disappearance of the starting compound (Fig. 2). 
The reaction was monitored by TLC, (hexane/ ethyl acetate, 80:20 v/v). After separation the organic layer was washed with water, dried over $\mathrm{Na}_{2} \mathrm{SO}_{4}$ and the solvent evaporated under reduced pressure, this gave a crude product which was purified by rapid chromatography (hexane/ethyl acetate, $100: 10 \mathrm{v} / \mathrm{v})$ to afford IK-3 (40 mg). The ${ }^{1} \mathrm{H}$ NMR spectrum of IK-3 was identical to that of the phenylhydrazine reduced product of $\mathbf{3 a}$ and hence is not reported here separately.

\subsection{Phospholipid liposomes and rat liver microsomes preparation}

Heterogenic multilamellar phosphatidylcholine liposomes were prepared immediately before the experiments by dissolving phospholipids in dichloromethane $\left(\mathrm{CH}_{2} \mathrm{Cl}_{2}\right)$ and removing the solvent under vacuo. The dried lipid film was hydrated with $5 \mathrm{mM}$ Tris- $\mathrm{HCl}$ buffer ( $\mathrm{pH}$ 7.4) containing $150 \mathrm{mM} \mathrm{NaCl}$ (buffer A), by vigorous shaking for $2 \mathrm{~min}$. The final liposome solution contained $13 \mathrm{mg}$ phospholipids/ml. In preliminary experiments the test compounds were also added, dissolved in $\mathrm{CH}_{2} \mathrm{Cl}_{2}$, to phospholipids before liposomal preparation.

Liver microsomes were obtained from male Sprague-Dawley rats (Charles River) by differential centrifugation as previously described (Benedetti et al., 1982). The microsomes were washed and resuspended in $50 \mathrm{mM}$ Tris-maleate buffer (pH 7.4) containing $150 \mathrm{mM} \mathrm{KCl}$, to a final concentration of $6.2 \mathrm{mg}$ protein $/ \mathrm{ml}$, and stored at $-70^{\circ} \mathrm{C}$. They were used after appropriate dilution with buffer A to obtain a microsomal protein content corresponding to $1.5 \mathrm{mg}$ protein/ $\mathrm{ml}$. The microsomal protein concentration was determined as reported (Bradford, 1976).

\subsection{Lipid peroxidation induction}

The reaction mixture contained in a final volume of $4 \mathrm{ml}$ : buffer A, $0.6 \mathrm{ml}$ liposomes $(8 \mathrm{mg}$ phospholipids) or $2.7 \mathrm{ml}$ microsomes $(4 \mathrm{mg}$ protein). This mixture with and without test compounds, dissolved in ethanol (20\% final concentration), was preincubated and then lipid peroxidation was induced by adding Fenton's
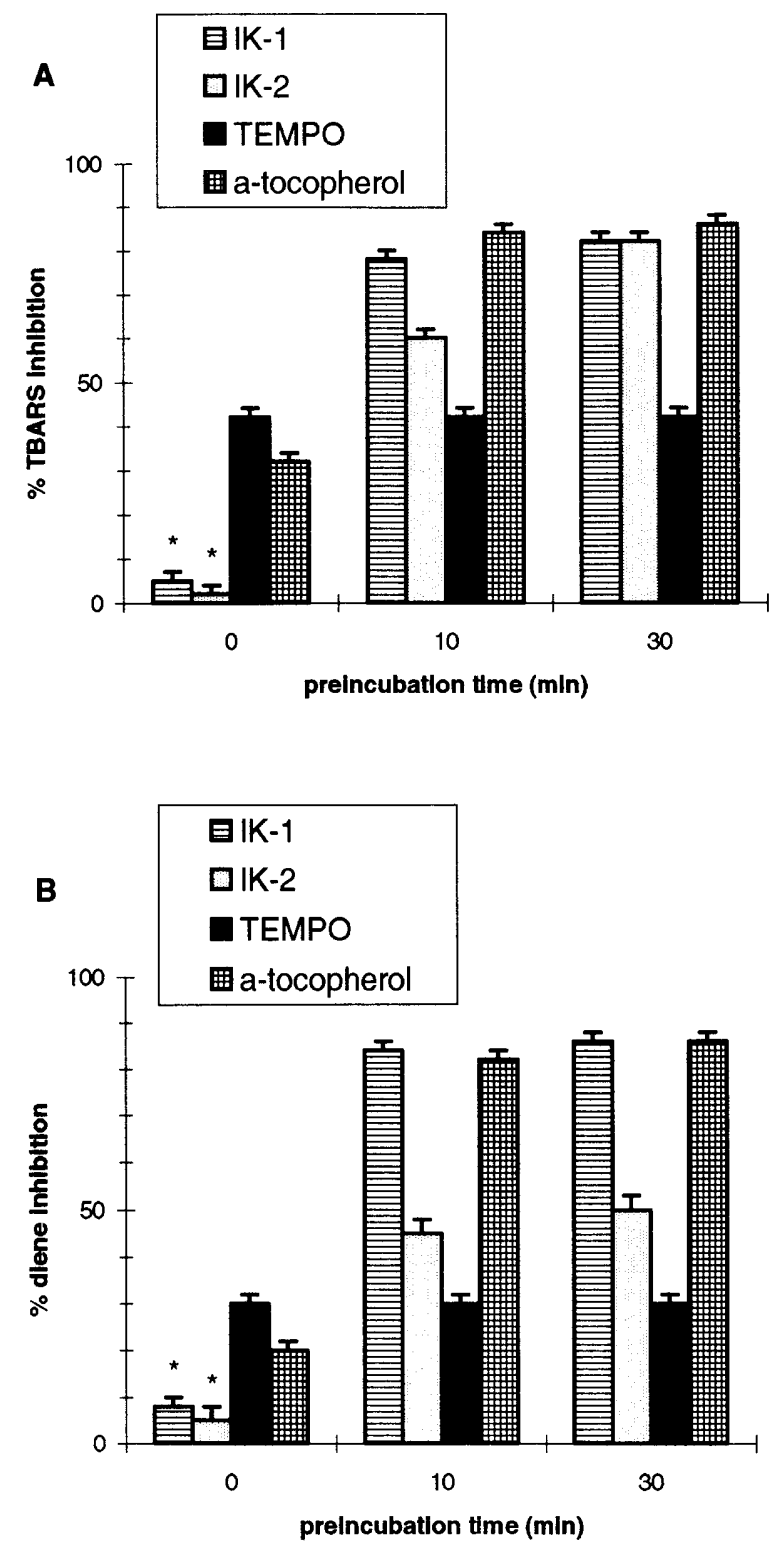

Fig. 3. Effect of preincubation time on the inhibition of TBARS and conjugated diene formation. Samples containing microsomes $(1 \mathrm{mg}$ protein $/ \mathrm{ml})$ and test compounds $(20 \mu \mathrm{M})$ added in ethanol $(20 \%$ final concentration), were preincubated for the indicated times. Fenton's reagent was added and aliquots for TBARS (A) and conjugated diene (B) evaluation were withdrawn after 30 and $90 \mathrm{~min}$, respectively. The percentage of TBARS and conjugated diene inhibition was determined with respect to induced controls (containing 20\% ethanol), showing absorbance values of $0.620 \pm 0.008$ and $0.960 \pm 0.012$, respectively. IC $_{50}$ (IK-1, IK-2, $\alpha$-tocopherol): $8 \pm 0.3 \mu \mathrm{M} ; \quad \mathrm{IC}_{50}$ (TEMPO): $20 \pm 3 \mu \mathrm{M}$. Values are the means \pm SE of three independent experiments. Statistical significance was determined using the Student's $t$-test. ${ }^{*} P>0.05$ vs. induced controls. 
reagent $\left(100 \mu \mathrm{M} \mathrm{FeSO}_{4}\right.$ and $\left.50 \mu \mathrm{M} \mathrm{H}_{2} \mathrm{O}_{2}\right)$ to generate $\mathrm{OH}^{*}$, or $50 \mathrm{mU} / \mathrm{ml} \mathrm{XO}$ and $1 \mathrm{mM}$ Xan to enzymatically generate anion superoxide radicals (Fridovich, 1970) or $8 \mathrm{mM} \mathrm{AMPH,} \mathrm{a} \mathrm{water}$ soluble azo-initiator generating peroxyl radicals (Niki, 1987; Halliwell et al., 1995). For all these induction conditions appropriate controls with and without $20 \%$ ethanol were run. The oxidation was performed at $37^{\circ} \mathrm{C}$ in a Dubnoff metabolic shaker bath under air atmosphere and in the dark. Aliquots of the reaction mixture were removed periodically and analysed as described below.

\subsection{Assay of lipid peroxidation products}

The formation of thiobarbituric acid reactive substances (TBARS) was measured on aliquots, corresponding to $1 \mathrm{mg}$ phospholipids or $1 \mathrm{mg}$ microsomal protein, added to $1 \mathrm{ml}$ of TBA $(0.75 \%$ dissolved in $0.5 \%$ sodium acetate), $1 \mathrm{ml}$ TCA $(10 \%)$ and $0.2 \mathrm{ml}$ BHT $(0.1 \%$ in ethanol) (Cordis et al., 1994). The mixture was heated at $100^{\circ} \mathrm{C}$ for $20 \mathrm{~min}$ and then centrifuged for $15 \mathrm{~min}$ at 10000 $\mathrm{rpm}$. The absorbance of the supernatant was measured at $535 \mathrm{~nm}$ against appropriate blanks. The formation of the conjugated diene was followed by recording the absorbance at $233 \mathrm{~nm}$. For this purpose aliquots of incubated liposomes $(0.5 \mathrm{mg}$ phospholipids), were dissolved in ethanol $(3 \mathrm{ml})$, whereas aliquots of incubated microsomes $(0.5 \mathrm{mg}$ protein), were extracted (chloroform/methanol, $2: 1 \mathrm{v} / \mathrm{v}$ ) and the residue dissolved in ethanol (3 ml) (Palozza and Krinsky, 1991). None of the test compounds interfered with the TBARS and conjugated diene assays.

\subsection{Evaluation of IK-1 amount, by HPLC analysis}

The IK-1 amount formed during the oxidation of IK-3 or decreased during IK-1 incubation was monitored in the reaction mixture by HPLC analysis. Liposomes (2 $\mathrm{mg}$ phospholipids/ml) or microsomes $(1 \mathrm{mg}$ protein $/ \mathrm{ml})$ were preincubated at $37^{\circ} \mathrm{C}$ in the presence of IK-3 or IK-1 $(20 \mu \mathrm{M})$ added in ethanol $(20 \%)$, then lipid peroxidation was induced. At different times aliquots $(100 \mu 1)$ were withdrawn and methanol $(60 \mu 1)$ was added to them; $80 \mu 1$ of the resulting solution were directly analysed by HPLC. Under these conditions the IK-1 retention time was $12 \mathrm{~min}$. Standard curves were prepared by adding different amounts of IK-1 $(2-40 \mu \mathrm{M})$ to liposomes or microsomes, but incubation was avoided. Aliquots $(100 \mu 1)$ were withdrawn and diluted as described above; the range of injected IK-1 amounts was $0.1-2$ nmol.

\section{Results and discussion}

The steroidic nitroxyls, IK-1/IK-2, were newly synthesized by a similar reaction sequence, starting with $5 \alpha$-cholestan-3-one and methyl $7 \alpha, 12 \alpha$ diacetoxy-3-oxo-5 $\beta$-cholan-24-oate, respectively (Fig. 1). The hydroxylamine IK-3 was also prepared from IK-1 (Fig. 2) to investigate the mechanism of IK-1 action. Structure and purity were established by physico-chemical methods. The cholestane and cholic acid nuclei were chosen as representatives of less (cholestane) and more polar (cholic acid) steroidic moieties. The IK-1/IK-2 activity was compared with that of known antioxidants: TEMPO, chosen for its ability to react mainly with primary radicals, (Mitchell et al., 1990; Voest et al., 1994; Nilsson et al., 1989) and $\alpha$-tocopherol for its chain-breaking antioxidant capability (Niki, 1987; Halliwell et al., 1995).

To check the inhibition ability of IK-1/IK-2 on Fenton's induced lipid peroxidation, we first used heterogenic multilamellar liposomal system and IK-1/IK-2 $(20 \mu \mathrm{M})$ were incorporated directly into the lipids before liposome preparation. They were found to actively reduce TBARS formation $(80 \%)$ but were unable to initiate lipid peroxidation in liposomal controls (data not reported). These positive results prompted us to search for solvents and preincubation times suitable for testing IK-1/IK-2 activity in a microsomal system. The best conditions for TBARS inhibition $(80 \%)$ were obtained when spin labels dissolved in ethanol (20\% final concentration), were added to the liposomal system which was then preincubated for $10 \mathrm{~min}$ before peroxidation induction. 
Table 1

Evaluation of decreased IK-1 amount and TBARS inhibition in lipid peroxidation induced systems

\begin{tabular}{|c|c|c|c|c|c|c|}
\hline \multirow[t]{2}{*}{ Incubation (min) } & \multicolumn{2}{|l|}{ Microsomes } & \multicolumn{2}{|l|}{ Heated microsomes } & \multicolumn{2}{|l|}{ Liposomes } \\
\hline & $\begin{array}{l}\% \text { TBARS inhibi- } \\
\text { tion }\end{array}$ & IK-1 (nmol) & $\begin{array}{l}\% \text { TBARS inhibi- } \\
\text { tion }\end{array}$ & IK-1 (nmol) & $\begin{array}{l}\% \text { TBARS inhibi- } \\
\text { tion }\end{array}$ & IK-1 (nmol) \\
\hline 0 & 0 & $20 \pm 0.5$ & 0 & $20 \pm 0.3$ & 0 & $20 \pm 0.6$ \\
\hline 10 & $80 \pm 2$ & $15 \pm 1.2$ & $80 \pm 2$ & $14 \pm 1.6$ & $66 \pm 4$ & $13 \pm 1.4$ \\
\hline 30 & $82 \pm 4$ & $14 \pm 0.8$ & $76 \pm 4$ & $10 \pm 0.8$ & $66 \pm 2$ & $9 \pm 0.6$ \\
\hline 60 & $82 \pm 2$ & $12 \pm 0.6$ & $70 \pm 2$ & $8 \pm 0.6$ & $66 \pm 2$ & $7 \pm 0.5$ \\
\hline 120 & $72 \pm 5$ & $10 \pm 0.4$ & $34 \pm 4$ & $4 \pm 0.4$ & $30 \pm 2$ & $4 \pm 0.4$ \\
\hline 240 & $68 \pm 4$ & $10 \pm 0.1$ & 0 & n.d. & 0 & n.d. \\
\hline
\end{tabular}

Evaluation of decreased IK-1 amount and TBARS inhibition in lipid peroxidation induced systems. Microsomes or heat pre-treated microsomes $(1 \mathrm{mg}$ protein $/ \mathrm{ml})$ and liposomes $(2 \mathrm{mg}$ phospholipids $/ \mathrm{ml})$, were preincubated for $10 \mathrm{~min}$ with IK-1 (20 $\mu \mathrm{M})$ added dissolved in ethanol (20\%). After the addition of Fenton's reagent aliquots were removed at the indicated time and used for the evaluation of the actual IK-1 amount by HPLC analysis and TBARS assay. n.d: value under the detection limit $(<2 \mathrm{nmol})$.

Similar conditions (same solvent and preincubation time set-up for liposomes) were then adopted to evaluate the antioxidant activity of IK-1/IK-2 in experiments carried out using rat liver microsomal system. Also in this system, IK$1 / \mathrm{IK}-2$ were not able to induce lipid peroxidation when incubated for up to $4 \mathrm{~h}$ in controls. The results (Fig. 3) showed that IK-1 and IK-2 actively inhibited TBARS production $(80 \%)$ when they were respectively preincubated for 10 and 30 min before the Fenton's reagent addition. An identical preincubation time was also required by $\alpha$-tocopherol which reached its highest inhibitory activity, to the same extent as IK-1 (84\%), after 10 min preincubation (without preincubation, the inhibition accounted for $30 \%$ ). In contrast TEMPO showed a lower antioxidant ability $(40 \%)$ regardless of the preincubation time. IK-1 and to a lesser extent IK-2, also inhibited the conjugated diene formation. The ethanol amount needed to dissolve the steroidic nitroxyls appears high. However, induced controls (liposomes and microsomes) run with and without $20 \%$ ethanol generated the same amount of TBARS and conjugated diene thus excluding any interference of ethanol in lipid peroxidation. This is in agreement with various reports showing that ethanol, even added to microsomes at $50 \mathrm{mM}$ concentration, does not affect lipid peroxidation (Shaw et al., 1984; Nakajima et al., 1992).
In some experiments both the concentration of IK-1 and the entity of TBARS formation were monitored as a function of the incubation time (Table 1). On comparing the behaviour of IK-1 incubated with microsomes, heat pre-treated microsomes and liposomes it was found that the IK-1 amount in the microsomes decreased significantly $(P<0.05)$ after $10 \mathrm{~min}$ incubation but reached a stable value, corresponding to $50 \%$ of the initial concentration after $120 \mathrm{~min}$; the inhibition of TBARS accounted for $72 \%$. On the contrary, in heat pre-treated microsomes and liposomes, the IK-1 amount decreased continuously and disappeared completely after $120 \mathrm{~min}$ as did TBARS inhibition. This led to our suspecting that during experiments in the presence of microsomes an enzyme-mediated process could partially restore IK-1 concentration from a possible transformation compound. Thus on the basis of various reports showing that many nitroxyl radicals in lipid peroxidation inhibition are reversibly reduced to the corresponding active hydroxylamines (Nilsson et al., 1989; Miura et al., 1993; Nilsson et al., 1990), we considered hydroxylamine IK-3 to be the more probable transformation product of IK-1 in microsomes. Thus IK-3 was prepared and experiments were performed to check its antioxidant ability and its possible reoxidation to IK-1. According to some authors, IK-3 could be transformed to IK-1 by superoxide anions (Rosen et al., 1982; Samuni et al., 1988; Belkin et al., 1987), 
by reactions dependent on a transition metal (Rosen et al., 1982) or by enzymes (Rosen and
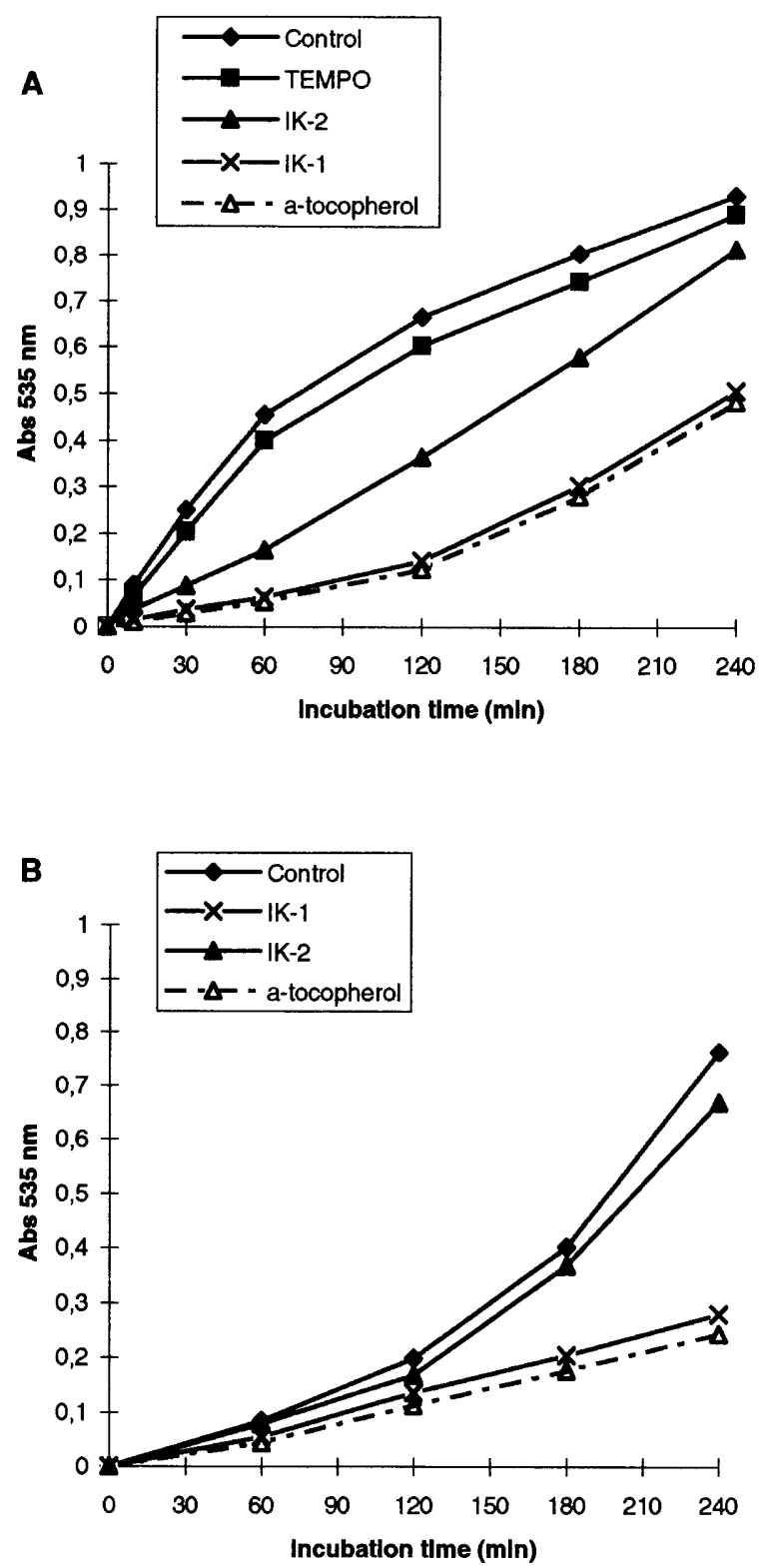

Fig. 4. Inhibition of TBARS formed by AMPH-induced lipid peroxidation. Microsomes (1 $\mathrm{mg}$ protein $/ \mathrm{ml}$ ) were preincubated for $30 \mathrm{~min}$ with the test compounds $(20 \mu \mathrm{M})$ added dissolved in ethanol $(20 \%)$, in the absence (A) or presence (B) of ascorbic acid $(300 \mu \mathrm{M})$. The peroxidation was induced by 8 $\mathrm{mM}$ AMPH. The formation of TBARS in induced controls (containing 20\% ethanol) (A) was linear for at least $60 \mathrm{~min}$ and the rate of radicals generation was $10.8 \times 10^{-9} \mathrm{M} \mathrm{s}^{-1}$.
Rauckman, 1977; Chen and Swartz, 1988; Chen et al., 1989; Iannone et al., 1990). In our experiments, when IK-3 $(20 \mu \mathrm{M})$ was preincubated for 10 min with microsomes then subjected to peroxidation by Fenton's reagent, the appearance of IK-1 (75\% of the added IK-3 amount) was evident and associated with an inhibition of the TBARS level ( $82 \pm 4 \%$; results not reported). On the contrary, IK-3 incubated with heat pre-treated microsomes and liposomes failed to show any formation of IK-1 or any ability to inhibit lipid peroxidation. Thus, there appeared the strong possibility that the oxidation of the inactive IK-3 to IK-1 occurred through an enzymatic microsomal system. However, the involvement of enzymatically generated superoxide anions was excluded by incubating IK-3 with heat pre-treated microsomes and inducing lipid peroxidation by $\mathrm{Xan} / \mathrm{XO}$, a system able to generate superoxide anions. In this case there was no depletion of TBARS with respect to the appropriate controls and HPLC revealed no IK-1 appearance. In the same system IK-1 showed its ability to inhibit TBARS formation $(60 \pm 2 \%)$. Thus an enzymatic process, similar to those observed for non steroidic hydroxylamine, should occur with IK-3.

Finally, since the behaviour of IK-1 appears similar to that of $\alpha$-tocopherol, IK- 1 could act as a chain-breaking antioxidant; this was checked by inducing lipid peroxidation in microsomes by $\mathrm{AMPH}$, an aqueous azo-initiator which generates peroxyl radicals. The results (Fig. 4A) show that IK-1 almost totally inhibits the formation of TBARS up to $120 \mathrm{~min}$, showing a radical scavenger activity like that of $\alpha$-tocopherol. After 120 min, the effect of IK-1 and $\alpha$-tocopherol starts to decrease, reaching 50\% inhibition at $240 \mathrm{~min}$. These experiments also investigated IK-2 but its antioxidant capability was lower and TBARS formation reached the control value in $240 \mathrm{~min}$. In parallel experiments TEMPO, the positive control, showed no significant protection against TBARS formation. To interpret the potential of IK-1/IK-2 as scavengers of peroxyl radicals in vivo, it was essential to ascertain whether or not there was any interaction with antioxidants (e.g. $\alpha$-tocopherol and ascorbic acid) as such interac- 
tion could possibly lead to a complete loss of antioxidant activity or to an indirect peroxidation initiation. This prompted us to incubate IK-1 and IK- 2 in the presence of ascorbic acid and $\alpha$-tocopherol, single or together in equimolar quantities $(20 \mu \mathrm{M})$, but no interference were observed; in fact IK-1 and IK-2 maintained their total activity and no TBARS formation was observed in no induced control (data not reported). However, ascorbic acid at very high concentration $(300 \mu \mathrm{M})$ significantly extended the antioxidant ability of IK-1 for up to 240 min incubation $(80 \%$ inhibition; Fig. 4B). This could be due to the reduction of IK-1 to IK-3 which, as we observed, can be reoxidated to IK-1 by enzymes.

In conclusion, we have presented evidence that the two stable steroidic nitroxyl radicals IK-1 and IK-2 possess properties that decrease lipid peroxidation in microsomes. The more lipophilic, IK-1, shows an inhibitory activity comparable to that of $\alpha$-tocopherol, confirming that a good affinity for cell membranes improves the activity of lipid peroxidation inhibitors. The results appear favourable indications for a possible use of these steroidic nitroxyls in vivo, provided their atoxicity is ascertained in cell cultures.

\section{Acknowledgements}

The authors are grateful to Prof. Mario Anastasia for his helpful comments and suggestions. This study was supported by a grant from the Ministero Università e Ricerca Scientifica e Tecnologica, Rome.

\section{References}

Allevi, P., Anastasia, M., Cajone, F., Ciuffreda, P., Sanvito, A.M., 1995a. Structural requirements of aldehydes produced in LPO for the activation of heat-shock genes in HeLa cells. Free Radic. Biol. Med. 18, 107-116.

Allevi, P., Cajone, F., Ciuffreda, P., Anastasia, M., 1995b. The first synthesis of Threo-and Erythro-(E)-4,5- dihydroxydec2-enals carbonyls related to the peroxidation of liver microsomal lipids. Tetrahedron Lett. 36, 1347-1350.

Ankel, E.G., Lai, C.S., Hopwood, L.E., Zivkovic, Z., 1987. Cytotoxicity of commonly used nitroxide radical spin probes. Life Sci. 40, 495-498.
Belkin, S., Mehlhorn, R.J., Hideg, K., Hankovsky, O., Packer, L., 1987. Reduction and destruction rates of nitroxide spin probes. Arch. Biochem. Biophys. 256, 232-243.

Benedetti, A., Fulceri, R., Ferrali, M., Ciccoli, L., Esterbauer, H., Comporti, M., 1982. Detection of carbonyl functions in phospholipids of liver microsomes in $\mathrm{CCl}_{4}$ and $\mathrm{BrCCl}_{3}$ poisoned rats. Biochim. Biophys. Acta 712, 628-638.

Bradford, M.M., 1976. A rapid and sensitive method for the quantitation of microgram quantities of protein utilizing the principle of protein dye binding. Anal. Biochem. 72, $248-254$

Chen, K., Swartz, H.M., 1988. Oxidation of hydroxylamines to nitroxide spin labels in living cells. Biochim. Biophys. Acta 970, 270-277.

Chen, K., Glockner, J.F., Morse, P.D., Swartz, H.M., 1989. Effects of oxygen on the metabolism of nitroxide spin labels in cells. Biochemistry 28, 2496-2501.

Cordis, G.A., Bagchi, D., Maulik, N., Das, D.K., 1994. Highperformance liquid chromatographic method for the simultaneous detection of malonaldehyde, acetaldehyde, formaldehyde, acetone and propionaldehyde to monitor the oxidative stress in heart. J. Chromatogr. 661, 181-191.

Esterbauer, H., Wäg, G., Puhl, H., 1993. Lipid peroxidation and its role in atherosclerosis. Br. Med. Bull. 49, 566-576.

Fridovich, I., 1970. Quantitative aspects of the production of superoxide anion radical by milk xanthine oxidase. J. Biol. Chem. 245, 4053-4057.

Gelvan, D., Saltman, P., Powell, S.R., 1991. Cardiac reperfusion damage prevented by a nitroxide free radical. Proc. Natl. Acad. Sci. USA 88, 4680-4684.

Halliwell, B., Gutteridge, J.M.C., Cross, C.E., 1992. Free radicals, antioxidants, and human disease: where are we now?. J. Lab. Clin. Med. 119, 598-620.

Halliwell, B., Aeschbach, R., Löliger, J., Aruoma, O.I., 1995. The characterization of antioxidants. Food Chem. Toxicol. $33,601-617$.

Iannone, A., Tomasi, A., Vannini, V., Swartz, H.M., 1990. Metabolism of nitroxide spin labels in subcellular fraction of rat liver. Biochim. Biophys. Acta 1034, 285-289.

Keana, J.F.W., Keana, S.B., Beethan, D., 1967. A new versatile ketone spin label. J. Am. Chem. Soc. 89, 3055-3056.

Lee, T.D., Keana, J.F.W., 1975. In situ reduction of nitroxide spin labels with phenylhydrazine in deuteriochloroform solution. A convenient method for obtaining structural information on nitroxides using nuclear magnetic resonance spectroscopy. J. Org. Chem. 40, 3145-3147.

Mitchell, B., Samuni, A., Krishna, M.C., DeGraff, W.G., Ahn, M.S., Samuni, U., Russo, A., 1990. Biologically active metal-independent superoxide dismutase mimics. Biochemistry 29, 2802-2807.

Miura, Y., Utsumi, H., Hamada, A., 1993. Antioxidant activity of nitroxide radicals in lipid peroxidation of rat liver microsomes. Arch. Biochem. Biophys. 300, 148-156.

Nakajima, T., Ikatsu, H., Okino, T., Wang, R.S., Murayama, N., Yonekura, I., Sato, A., 1992. Enhancement of ethanolinduced lipid peroxidation in rat liver by lowered carbohydrate intake. Biochem. Pharmacol. 43, 245-250. 
Niki, E., 1987. Antioxidants in relation to lipid peroxidation. Chem. Phys. Lipids. 44, 227-253.

Nilsson, U.A., Olsson, L.I., Carlin, G., Bylund-Fellenius, A.C., 1989. Inhibition of lipid peroxidation by spin labels. J. Biol. Chem. 264, 11131-11135.

Nilsson, U.A., Carlin, G., Bylund-Fellenius, A.C., 1990. The hydroxylamine OXANOH and its reaction product, the nitroxide OXANO; act as complementary inhibitors of lipid peroxidation. Chem.-Biol. Interact. 74, 325-342.

Palozza, P., Krinsky, N.I., 1991. The inhibition of radical-initiated peroxidation of microsomal lipids by both $\alpha$-tocopherol and $\beta$-carotene. Free Radic. Biol. Med. 11, 407-414.

Rosen, G.M., Rauckman, E.J., 1977. Formation and reduction of a nitroxide radical by liver microsomes. Biochem. Pharmacol. 26, 675-678.

Rosen, G.M., Finkelstein, E., Rauckman, E.J., 1982. A method for the detection of superoxide in biological systems. Arch. Biochem. Biophys. 215, 367-378.
Samuni, A., Krishna, C.M., Riesz, P., Finkelstein, E., Russo, A., 1988. A novel metal-free low molecular weight superoxide dismutase mimic. J. Biol. Chem. 263, 17921-17924.

Samuni, A., Mitchell, J.B., DeGraff, W., Krishna, M.C., Samuni, U., Russo, A., 1991. Nitroxide SOD-mimics: modes of action. Free Radic. Res. Commun. 12, 187-194.

Shaw, S., Jayatilleke, E., Lieber, C.S., 1984. The effect of chronic alcohol feeeding on lipid peroxidation in microsomes: lack of relationship to hydroxyl radical generation. Biochem. Biophys. Res. Commun. 118, 233-238.

Still, W.C., Kahn, M., Mitra, A., 1978. Rapid chromatographic technique for preparative separations with moderate resolution. J. Org. Chem. 43, 2923-2925.

Voest, E.E., van Acker, S.A.B.E., van der Vijgh, W.J.F., van Asbeck, B.S., Bast, A., 1994. Comparison of different iron chelators as protective agents against acute doxorubicin-induced cardiotoxicity. J. Mol. Cell. Cardiol. 26, 1179-1185.

von Grand, R., Reichstein, T., 1945. Ber Gallens uren und verwandte Stoffe. Derivate der Cholsäure. Helv. Chim. Acta 8, 344-349. 